\title{
Chronic tension-type facial pain- a pilot study on HTTLPR genetic polymorphisms*
}

\author{
A.M. Agius ${ }^{1}$, R. Muscat ${ }^{2}$ \\ 'Department of Surgery, Faculty of Medicine and Surgery, University of Malta, Msida, Malta \\ ${ }^{2}$ Department of Physiology and Biochemistry, Faculty of Medicine and Surgery, University of Malta, Msida, Malta
}

Rhinology Online, Vol 2: 125 - 133, 2019

http://doi.org/10.4193/RHINOL/19.036

*Received for publication:

November 17, 2019

Accepted: December 23, 2019

Published: December 27, 2019

\begin{abstract}
Background: This study looked at the association between serotonin transporter gene variants and with chronic persistent tension-type facial pain. Known as triallelic 5-HTTLPR, the serotonin transporter gene-linked polymorphic region and its rs 25531 polymorphism have been linked to alterations in pain perception.
\end{abstract}

Patients and methods: Genotype polymorphism analysis was carried out in 26 patients with chronic tension type facial pain unresponsive to or recurring after treatment with amitriptyline. Findings were compared to 33 asymptomatic age-and gendermatched controls. Blood serotonin levels in these two groups were also determined.

Results: Consistent with previous studies, patients with chronic pain had significantly lower blood serotonin compared to controls. In all genotypes, blood serotonin was low compared to controls and this difference was significant in patients homozygous for the L allele.

Conclusion: In this small pilot study, patients with the LL genotype seemed to have the best clinical outcome after three-year follow-up.

Key words: chronic, tension-type pain, facial pain, blood serotonin levels, 5-HTTLPR

\section{Introduction}

Chronic tension-type headache and facial pain is due to central sensitisation in the thalamus caused by enhanced responsiveness of spinal dorsal horn neurons ${ }^{(1)}$. Distal projections of serotonergic neurons from the rostroventral medulla in the brainstem exert a descending tonic pain inhibition to the spinal cord ${ }^{(2,3)}$; serotonergic dysfunction thus enhances pain transmission. At synaptic level the serotonin transporter (5-HT transporter or 5-HTT) clears serotonin that has been released by the presynaptic neuron terminal and is the main mechanism controlling synaptic serotonin levels ${ }^{(4)}$. Reduction in serotonin re-uptake enhances its effect over a wider synaptic field ${ }^{(5)}$. Platelets are a convenient biochemical model for central serotonergic neurons since they share the same identical uptake protein ${ }^{(6,7)}$. Blood serotonin levels reflect intraplatelet serotonin, because 90 to $99 \%$ of blood serotonin is stored inside platelets ${ }^{6,}$ ${ }^{8,9)}$. Platelet serotonin levels in individuals with chronic tension- type headache tend to be low ${ }^{(10)}$. Similarly, patients with chronic midfacial tension-type pain (CMFP) had significantly low whole blood serotonin levels compared to controls ${ }^{(11)}$.

The great majority of patients with CMFP are women ${ }^{(12)}$. In women with CMFP, treatment with low-dose amitriptyline significantly reduced pain frequency and intensity and this was associated with a non-significant reduction in blood serotonin. When taking the beta blocker pindolol in tandem with amitriptyline, blood serotonin was reduced even further to a significant extent while also significantly reducing pain frequency and intensity. In the presence of amitriptyline, pindolol acts as a partial agonist to the 5-HT $1 \mathrm{~A}$ receptor on the somatodendritic area of serotonergic neurons in the brainstem. Stimulation of the $5-\mathrm{HT}$ $1 \mathrm{~A}$ receptor enhances peripheral serotonergic discharge in projection areas with enhanced inhibition of pain in the face ${ }^{(11)}$. 
The serotonin uptake transporter protein (5-HTT) in platelets and in the central nervous system has an identical amino acid structure ${ }^{(13)}$. The human 5-HTT gene has been successfully cloned $^{(14)}$ and is one of a family of similar neurotransmittercarrying transport proteins. It contains 630 amino acids with 12 transmembrane domains ${ }^{(15)}$ and transports serotonin together with $\mathrm{Na}^{+}$and $\mathrm{Cl}^{-}$ions into the neuron while transporting $\mathrm{K}^{+}$ions outwards ${ }^{(5)}$. 5-HTT is coded by a single gene (SLC6A4) which is found on chromosome $17 q 12^{(13)}$. The most studied polymorphism variant has a 43 base pair insertion/deletion in the 5 -regulatory promoter region of the gene. This is known as the 5-HTT linked polymorphic region or 5-HTTLPR and occurs in the population as two prevalent alleles ${ }^{(16)}$. The short variety is expressed with 14 amino acids (S-allele) and the long one with 16 amino acids (L-allele) ${ }^{(17)}$. Individuals with the S-allele have lower 5-HTT activity than those with the L-allele ${ }^{(17)}$ and patients homozygous for the short form of 5-HTTLPR take up serotonin at about half the normal rate ${ }^{(18,19)}$. Individuals may express $L L$, SS or LS genotypes. An Adenosine to Guanine substitution (rs25531) in the 5-HTT promoter region has also been described. In this single nucleotide polymorphism (SNP) the G-allele, which is found in phase with the L-allele, reduces the serotonin re-uptake of the L-allele to S-allele levels ${ }^{(20)}$. These two polymorphisms, when studied jointly, have been referred to as tri-allelic 5-HTTLPR.

Some alleles may be associated with a higher risk of developing chronic pain conditions ${ }^{(21)}$. Korean patients with chronic tension-type headache and analgesic-overuse have been demonstrated to have a relatively high incidence of the short allele (22). Women with the short allele have been shown to have an increased susceptibility to depression and anxiety ${ }^{(23)}$. Individuals with the short allele have a reduced serotonin uptake protein activity in platelets ${ }^{(24)}$.

Tri-allelic 5-HTTLPR has been implicated in subjective pain perception ${ }^{(25)}$. For example, the short allele of the serotonin transporter gene has been associated with a negative emotional response to pain which is modulated at supraspinal level (26). In a study on 67 healthy males and 60 healthy females using heat pain stimuli, carriers of the S-allele, with SS or LS genotypes had lower pain thresholds with an increased emotional reaction to pain ${ }^{(27)}$. Patients with trigeminal neuralgia have a higher prevalence of the 'SS' genotype than healthy age- and sex- matched controls ${ }^{(28)}$. There is a high incidence of depression in patients with chronic pain. In 277 patients with chronic pain, depression scores were significantly higher in patients with the 'SS' allele for 5-HTTLPR compared to those with the 'LL' allele (29).

Considering that lower pain thresholds have been found in individuals with SS and SL genotypes and the fact that that women with CMFP had lower blood serotonin levels which were further reduced following the combination treatment of amitriptyline
Table 1. Study inclusion criteria.

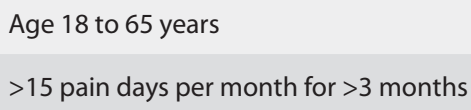

Bilateral, pressing or aching pain, affecting mid-face but may involve head

Normal ENT examination, fundoscopy, cranial nerves, blood pressure Normal nasal endoscopy and CT sinuses/brain

Relapse of pain after initial response to amitriptyline or no response to analgesics or amitriptyline.

Table 2. Study exclusion criteria.

$<18$ years of age or $>65$ years
Rhinorrhoea, postnasal drip, hyposmia
Sinus surgery within 2 years
Previous facial or ophthalmic Herpes Zoster
Pregnancy
Barotrauma, Facial trauma
Temporomandibular joint dysfunction and pain of dental origin
Patients on antidepressants, hypnotics, beta-blockers, clopidrogel,
aspirin (platelet activators)
$>1$ attack migraine per month
Central Nervous System Degenerative disease or tumours
Substance or alcohol abuse
Hamilton Score $>7$ (clinical depression)
Medication overuse headache
CT mucosal thickening $>3 \mathrm{~mm}$

and pindolol, this study investigated whether different serotonin transporter genotypes are associated with CMFP in women.

\section{Materials and Methods}

Patients were recruited from a community based general otorhinolaryngology practice in Malta and blood samples were collected after informed consent was obtained and patients were given a full description of the study. Demographic and clinical data were stored in anonymised format for analysis. This study was approved by the University of Malta Ethics committee. Patients were recruited between 1 June 2014 and 30 November 2017.

The recruitment inclusion and exclusion criteria are listed in Tables 1 and 2; only patients between 18 and 65 years old were recruited. Pregnant women, patients with facial trauma or with pain due to changes in ambient pressure such as flying or diving were excluded. Patients with temporomandibular dysfunction with clicking, tenderness of the temporomandibular joint, or with dental pain related to thermal sensitivity or percussion of the teeth were excluded. A standard patient history was taken as shown in Table 3. 
Table 3. Structured Clinical Interview for facial pain patients and their follow-up.

\section{Length of history}

Site: periorbital, paranasal, cheeks, frontal, vertex, occipital, temporalunilateral, bilateral

Quality: pressing, aching, throbbing or other

Duration, frequency and intensity

Presence of: photophobia, nausea, vomiting

Presence of: nasal obstruction, postnasal drip, rhinorrhoea, hyposmia, cough, fever, halitosis, toothache, ear pressure, fatigue,

Past history of migraine, family history of migraine Past history of systemic illness (such as lung disease) Past history of atopy and skin test positivity

Details of past of nasal surgery

Cigarette smoke exposure

Analgesic use -type and dose

Nasal endoscopy: normal, pus, polyps, mucosal oedema CT results: normal, rhinitis, sinusitis, anatomical abnormality

Final diagnosis

Chronic persistent mid-facial tension type pain was defined as bilateral symmetrical pressing tension-type pain according to International Headache Society criteria (IHS version III, 2013) (30) $^{(2)}$ that persisted despite treatment with amitriptyline $10 \mathrm{mg}$ daily for 8 weeks or that recurred immediately on stopping amitriptyline.

Patients had an ENT examination, cranial nerve examination and fundoscopy to exclude papilloedema and their blood pressure was checked. Nasal endoscopy was carried out and those patients with intranasal pus or polyps were excluded. Those with oedematous mucusa were included since in previous local studies nasal mucosal oedema was a non-specific finding having no association with sinusitis ${ }^{(31,32)}$. A computed tomogram of their brain and sinuses with coronal and axial cuts to exclude sinusitis and intracranial pathology was carried out. Computed tomography has for several years been considered the gold standard for evaluation of the paranasal sinuses ${ }^{(33)}$, especially when correlated with nasal endoscopy ${ }^{(34)}$. Patients with sinus mucosal thickening of over $3 \mathrm{~mm}$ on the CT were excluded. Those patients with a history of psychiatric illness or those on any antidepressant, antipsychotic or hypnotic treatment were excluded since such individuals were suspected to have dysfunction of their serotonergic pathways and headaches have been associated with depression ${ }^{(35,36)}$. As with previous studies 11 the Hamilton questionnaire was used to assess mood, feelings, insomnia, attitude towards work and somatic symptoms. Only those patients scoring up to 7 were included in this study, a Hamilton score of over 20 being strongly indicative of a depressive disorder ${ }^{(37)}$.

Individuals with medication-overuse headaches were excluded as it was determined that these constituted a particular group that was difficult to treat and whose medication may have altered serotonin reuptake activity. Patients with substance or alcohol abuse were also excluded for the same reason. Five patients previously on antidepressants were ensured a 'washout' period of two weeks before starting other treatment. Any patients with intracranial tumours or neurological degenerative disease such as multiple sclerosis were excluded.

\section{Sampling and Laboratory analysis \\ Blood serotonin}

Whole blood serotonin was estimated in 26 patients with persistent chronic tension-type facial pain and 33 healthy age- and gender-matched controls. Over ninety percent of blood serotonin is stored within platelets $(6,9,38)$ with the remainder in the plasma. For 48 hours prior to the test, patients were instructed to avoid foods high in tryptophan (the metabolic precursor of serotonin) such as tea, coffee, nuts, avocado, pineapple, tomatoes, plums, eggplant and chocolate. This was done to enable maximal uptake of plasma serotonin into the platelets prior to the test so that when taken, the whole blood serotonin would more closely reflect intra-platelet serotonin. The dietary restrictions were also intended to avoid the variation possible in hightryptophan diets, which have the potential to increase whole blood serotonin by up to $16 \%{ }^{(38)}$. Those patients taking drugs that alter platelet activation, such as aspirin or clopidrogel, were excluded as activation releases serotonin into the plasma.

Healthy controls were also required to avoid foods high in tryptophan for 2 days before their blood test.

Whole venous blood was collected at the St James Hospital laboratory, Malta using a pre-cooled heparinized plastic bottle and immediately frozen since serotonin levels are very sensitive to temperature. Samples were packed on dry ice in an insulated transport box, transported by courier to Biomnis laboratories in Lyon, France and analysed using High Performance Liquid Chromatography (HPLC) with electrochemical detection. Each HPLC analysis was preceded by internal standard calibration using standard solutions. Laboratory analysis was carried out by an observer with no knowledge of the headache condition of the patients or the controls.

To estimate intra-platelet serotonin a blood sample requires that it undergo immediate centrifugation to separate the plasma, which is then decanted off, from the platelet pellet. Centrifugation may disrupt platelets leading to release of serotonin into the plasma compartment while reducing platelet volume. Therefore, measurement of whole blood serotonin is preferable and more reliable ${ }^{(38)}$ even if in this way one may not be able to differentiate between platelet and plasma values.

An information sheet was supplied to the patients and the corresponding author (AA) was on hand for guidance or questions. 
Table 4. Sequence of primers used for the amplification of the 5-HTTLPR (BioneerR).

$\begin{array}{ll}\text { 5-HTT-Forward } & \text { TCCTCCGCTTTGGCGCCTCT } \\ \text { 5-HTT-Reverse } & \text { TGGGGGTTGCAGGGGAGATC }\end{array}$

Patients were individually consented for entry into the study and were given the option to withdraw at any time.

\section{Genotyping}

DNA preparation. Blood samples from patients were collected in EDTA Vacutainer tubes. A volume of $200 \mu \mathrm{l}$ of blood was then used for DNA extraction using the Accuprep Genomic DNA extraction kit (BioneerR). The DNA was then collected in $40 \mu \mathrm{L}$ of elution buffer.

\section{Amplification of 5-HTTLPR}

For each sample the 5-HTT linked polymorphic region (5-HTTLPR) was amplified by Polymerase Chain Reaction (PCR) using the primers outlined in Table $4{ }^{(29)}$. The reaction mixture consisted of 1XPCR buffer, MgCl2 dNTPs, Taq polymerase, forward and reverse primers and DNA. Samples were amplified on a PCR instrument (GeneAMP9700, Applied Biosystem) using the following thermal profile: $95^{\circ} \mathrm{C}$ for ten minutes, 30 cycles of $95^{\circ} \mathrm{C}$ for one minute, $62^{\circ} \mathrm{C}$ for one minute and $72^{\circ} \mathrm{C}$ for one minute and a final $72^{\circ} \mathrm{C}$ incubation for five minutes.

PCR products were then run in a $2.5 \%$ agarose gel stained with ethidium bromide which bound to the DNA. The DNA was run through the gel while a voltage of $200 \mathrm{~V}$ was applied. After the run, the gel was visualised under Ultraviolet light.

The rate of DNA migration in the gel was dependent on the size of the DNA. Smaller fragments migrated faster down the gel than larger fragments. Depending on the 5-HTTLPR genotypes, SS, LS and LL DNA bands were observed.

As seen in Figure 1, LS was characterised by two bands, an upper one representing the $L$ allele and a lower one representing the $\mathrm{S}$ allele. In comparison, an LL allele was represented by a single band that fell in line with the upper component of LS while SS was represented by a single band falling in line with the lower band of the LS.

Sequencing of the rs25531 single nucleotide polymorphism (SNP)

The rs25531 Adenosine to Guanine SNP was analysed by sequencing the 5-HTTLPR PCR product. The sequencing reaction was done using the BigDyeR Terminator v3.1 cycle sequencing kit (Applied Biosystems) and the forward primer as outlined in Table 4. The product was then run on the capillary electrophoresis genetic analyser 3130 (Applied Biosystem). Part of the sequencing data and the different results obtained for rs25531 are shown in Figure 2.

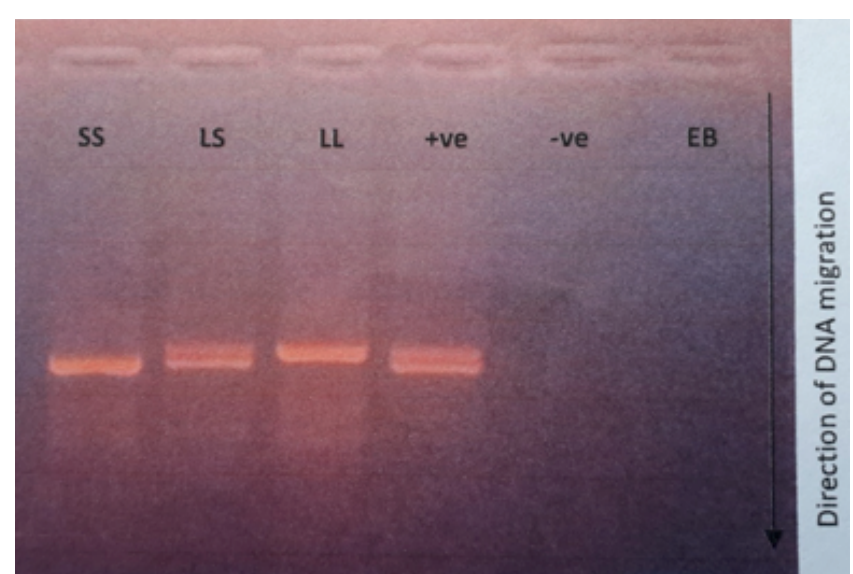

Figure 1. Agarose gel with DNA bands of the different genotypes (SS, LS and LL), positive control, negative control and extraction blank (EB) respectively. The lighter short DNA migrates further down than the heavier long one.

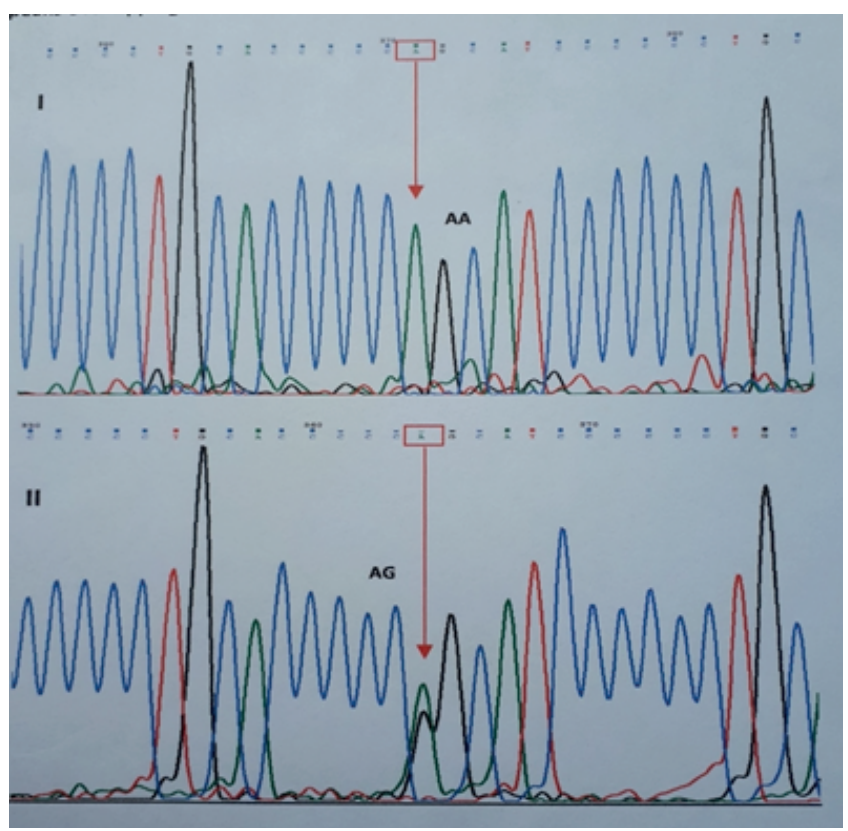

Figure 2. Section of the sequencing data surrounding the region of the Single Nucleotide Polymorphism rs25531. In diagram I (upper) the genotype AA is represented only by the presence of the Adenosine peak, in green. Diagram II (lower) shows the presence of the Adenosine (green) and Guanine (black) peaks which overlap.

\section{Results}

Twenty-six patients with chronic persistent mid-facial tension type pain (CMFP) satisfying the criteria laid out in table 1 were recruited. There were 23 women and 3 men. As with previous studies with facial pain ${ }^{(11,12)}$, the overwhelming majority of patients were women and significant gender trends emerged during analysis when excluding male patients. It was therefore decided to report the results for the 23 women while excluding men 
Table 5. Clinical symptoms in 23 patients with the different genotypes. The symptom spectrum is similar in the three types.

\begin{tabular}{lccc}
\hline Genotype & SS $(\mathbf{n}=\mathbf{4})$ & LS $(\mathbf{n}=13)$ & LL $(\mathbf{n}=6)$ \\
\hline $\begin{array}{l}\text { Mean pain Frequency } \\
\text { (pain days per week) }\end{array}$ & $5.3 \pm 2.1$ SD & $5.4 \pm 2.0$ SD & $6.7 \pm 0.6$ SD \\
$\begin{array}{l}\text { Mean pain intensity (vi- } \\
\text { sual analogue score 1-10) }\end{array}$ & $5.9 \pm 2.0$ SD & $7.2 \pm 1.9$ SD & $7.3 \pm 0.6$ SD
\end{tabular}

Table 6. Serotonin levels in female patients are lower than those in female controls ( $\mu \mathrm{g} / \mathrm{L})$. The difference between patients and controls is statistically significant for those having the LL genotype (student's t test $\mathrm{p}<0.03)$.

\begin{tabular}{|c|c|c|c|}
\hline Genotype & SS & LS & LL \\
\hline $\begin{array}{l}\text { Chronic Facial pain } \\
\text { women }(n=23)\end{array}$ & $\begin{array}{c}162 \pm 85 S D \\
(n=4)\end{array}$ & $\begin{array}{c}174 \pm 63 S D \\
(n=13)\end{array}$ & $\begin{array}{c}143 \pm 59 S D \\
(n=6)^{*}\end{array}$ \\
\hline Controls women $(n=31)$ & $\begin{array}{c}212 \pm 82 S D \\
(n=7)\end{array}$ & $\begin{array}{c}187 \pm 41 S D \\
(n=13)\end{array}$ & $\begin{array}{c}199 \pm 54 \text { SD } \\
(n=11)^{*}\end{array}$ \\
\hline
\end{tabular}

Two female patients had concomitant migraine but they were included because they only had up to 1 attack monthly, within the criteria established in previous studies ${ }^{(39,40)}$. The mean age of 23 female patients was $33.4 \pm 10.2$ standard deviation (SD) years, ranging from 20 to 39 years. They had a mean history of pain of $69 \pm 51$ months SD. Mean pain intensity based on visual analogue scale of 1 to 10 was $6.9 \pm 1.8$ SD. The mean pain frequency per week was $5.6 \pm 1.8$ SD pain days out of 7 . Table 5 shows the mean pain frequency and intensity in the different genetic subgroups which were broadly similar and demonstrate the pain burden in these patients.

The 31 age-matched female controls were recruited from patients having elective surgery, on the basis that they had no history of chronic facial pain. Their mean age was $32.4 \pm 11.1$ SD years. The mean blood serotonin level in 23 female patients was $164 \pm 64 \mu \mathrm{g} / \mathrm{L}$ SD. The mean blood serotonin level in controls was $197 \pm 56 \mu \mathrm{g} / \mathrm{L}$ SD. This was significantly higher than patients ( $p=0.03, t$ test assuming unequal variances).

Table 6 compared mean blood serotonin level in the three genotypes of patients and controls. Chronic facial pain patients of all genotypes had a lower blood serotonin compared to controls. The blood serotonin in women with chronic pain having the SS genotype was less than in controls but was not statistically significant ( $p=0.19$, $t$ test assuming unequal variances). Similarly, women with pain having the LS genotype had a lower blood serotonin than control women with the same genotype but the difference was not statistically significant $(p=0.27, t$ test assuming unequal variances). The difference in blood serotonin
Table 7. Number and percentage of women with chronic pain and female controls having the SS, LS or LL genotype (the difference is not significant, chi squared test $\mathrm{p}=0.6$ )

\begin{tabular}{|lccc|}
\hline Genotype & SS & LS & LL \\
\hline $\begin{array}{l}\text { Chronic Facial pain }(n=23) \\
\begin{array}{l}\text { Healthy control women } \\
(n=31)\end{array}\end{array}$ & $4(17 \%)$ & $13(56 \%)$ & $6(27 \%)$ \\
\hline
\end{tabular}

Table 8. The percentage long-term significant clinical improvement in facial pain in the different genotypes after three-year follow-up. Patients with LL genotype did best but the statistical difference is non-significant, (chi squared test, $p=0.1$ )

\begin{tabular}{lccc} 
Genotype & SS & LS & LL \\
$\begin{array}{l}\text { Patients clinically impro- } \\
\text { ved and } \%(n=9)\end{array}$ & $0(0 \%)$ & $5(38 \%)$ & $4(67 \%)$ \\
$\begin{array}{l}\text { Patients remaining the } \\
\text { same }(n=18)\end{array}$ & 4 & 8 & 2 \\
\hline
\end{tabular}

levels between patients and controls in the LL genotype was significant $(p=0.03)$.

Table 7 shows the numbers and percentages of female patients and female controls having LL, LS and SS genotypes. The genotype distribution in patients and controls was very similar. The presence of the polymorphism with Guanine replacing Adenosine (rs25531) was investigated as this polymorphism has been reported to affect function of the serotonin uptake protein. It was only present in two control individuals, one with the LL genotype and one with the LS genotype, so this did not seem relevant to the development of chronic facial pain in the Maltese population.

Patients were followed up for three years. Their outcome was classified into significant clinical improvement, where pain frequency or intensity was reduced by $50 \%$ or more according to previous studies ${ }^{(11)}$, or same, where pain continued without relief. From 6 women with the LL genotype, four (67\%) were improved at three years. In the 13 women with the LS genotype, five were improved at three years (38\%), while in those with the SS genotype, none were improved at three years since they all continued to have chronic pain ( $0 \%$ well, Table 8 ).

\section{Discussion}

Central sensitization and Diffuse Noxious Inhibitory Controls (DNIC)

Frequent nociceptive input from facial and cranial muscles in patients with infrequent episodic headache leads to secondorder neuron sensitisation in the trigeminal subnucleus caudalis 
and dorsal horn of the cervical spinal cord. As a result, patients subsequently develop frequent episodic tension-type headache. Continuous nociceptive stimulation in these patients sensitizes third order neurons in the thalamus and somatosensory cortex. Patients thus go on to develop chronic tension-type headache and exhibit hypersensitivity to stimuli in cephalic and extracephalic regions ${ }^{(41)}$.

In the sensitized state, the afferent A $\beta$-fibres that normally inhibit nociceptive $A \delta$ - and $C$-fibres by presynaptic inhibition in the dorsal horn may instead stimulate ascending second-order neurons ${ }^{(42)}$. Moreover, the effect of $A \delta$ - and C-fibre stimulation is potentiated and the receptive fields of dorsal horn neurons are expanded ${ }^{(43)}$. Nociceptive input as well as its transmission to supraspinal structures would therefore be increased in central sensitization ${ }^{(44)}$.

Development of chronic pain such as seen in tension-type headache or fibromyalgia may therefore be due to a dysfunction in central pain inhibitory mechanisms. In so-called DNIC or diffuse noxious inhibitory controls, pain fibre stimulation is suppressed at the level of the spinal cord if multiple peripheral noxious stimuli converge. For example, in normal individuals subjected to heat stimulation at the thigh, further painful electrical stimuli at the forearm or head shows a higher pain threshold. This endogenous supraspinal pain modulation system is deficient in patients with chronic tension-type headache and their pain thresholds on further pain stimulation are significantly lower ${ }^{(45)}$. The term DNIC has recently been replaced by Conditioned Pain Modulation (CPM) ${ }^{(46)}$.

\section{Conditioned Pain Modulation (CPM)}

Patients with chronic tension-type headache and fibromyalgia may be unable to activate their CPM ${ }^{(47,48)}$ and the balance is shifted from pain inhibition towards pain facilitation.

In a study on 191 healthy volunteers, carriers of the serotonin re-uptake protein long allele have been shown to have a significantly higher pain modulation compared to carriers of the short allele ${ }^{\left({ }^{(4)}\right)}$. In a recent review of the literature, Hermans et al concluded that long allele carriers had better CPM ${ }^{(50)}$. The results of the current study indicate better long-term pain control in LL individuals.

There is an inherent difficulty with pain studies as conditions are not easily standardized ${ }^{(51)}$. Environmental influences, primarily stress, play a very important role in chronic tension-type pain. Hariri et al assessed the response to fearful stimuli using functional MRI and showed increased excitability of the emotionprocessing areas of the brain in patients with the ' $S$ ' allele. This means that increased anxiety-related responses in these individuals may in turn, precipitate tension-type pain ${ }^{(52)}$. It was not easy to recruit patients for this study as they had to

\section{LL Genotype}
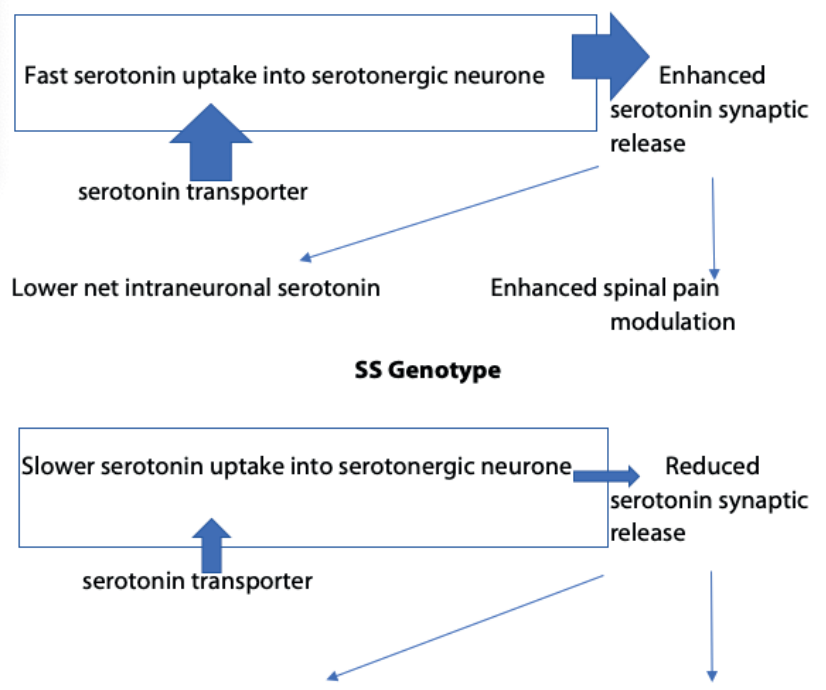

Higher net intraneuronal serotonin

Reduced spinal pain modulation

Figure 3. Diagram with hypothesis explaining intraneuronal serotonin levels in genetic subgroups.

satisfy the exhaustive list of exclusion criteria. Limited study numbers therefore have an impact on the study results and thus these need to be viewed with some caution.

The relative frequencies of the $L$ and $S$ alleles differ in various populations, with the $L$ variant being twice as common in European compared to Asian populations ${ }^{(53,54)}$. The frequencies of SS, LS and LL alleles have been determined in a study on cord blood samples of 323 males and 307 females in Malta and were found to be $21.2 \%, 47.4 \%$ and $31.1 \%$ respectively - almost identical to the findings in this pilot study ${ }^{(55)}$. This supported the validity and accuracy of this pilot study even though the numbers were small.

Blood serotonin is almost exclusively platelet serotonin, which reflects intraneuronal levels ${ }^{(38)}$. Low blood serotonin in patients thus reflects low intraneuronal serotonin in the central nervous system. Patients with all genotypes had a lower blood serotonin than in matched controls. This difference was significant in those having the LL genotype ( $p=0.03)$.

Explanation for this can be extrapolated from a previous investigation by the same authors where serial blood serotonin samples were taken in a randomized controlled study on 62 patients with CMFP ${ }^{(56)}$. Here patients were divided into three groups: a control group having placebo, a second group treated with $10 \mathrm{mg}$ amitriptyline daily and a third group receiving the combination treatment of amitriptyline $10 \mathrm{mg}$ with pindolol $10 \mathrm{mg}$ daily.

In the control group blood serotonin levels remained the same over 8 weeks while pain frequency and intensity remained 
the same. In the amitriptyline group, serotonin levels went down but not significantly, while pain scores at the same time significantly decreased. In the amitriptyline with pindolol group, serotonin was significantly reduced and this was also associated with a very significant reduction in pain scores. Therefore the third group in the randomized trial with the most effective pain control showed the largest reduction in blood serotonin (11).

It was likely that pindolol enhanced serotonin release from serotonergic neurons via its action on the $5-\mathrm{HT} 1 \mathrm{~A}$ receptors thus resulting in high synaptic serotonin and enhanced pain control. Less net serotonin would have been eventually left inside the neuron, and this is reflected in lower blood serotonin levels in the platelet model (Figure 3).

There is a trend (Table 6) for blood serotonin to be reduced in patients with SS and LS genotypes compared to controls but this reduction is not significant. Blood serotonin in LL patients is significantly lower than controls. In LL patients the low blood serotonin compared to the other two groups is thought to represent a drop in intraneuronal serotonin due to distal synaptic release resulting in better pain control.

It is hypothesised that LL patients show the best pain control because they have a more efficient serotonin uptake and release. The high serotonin turnover gives clinical success despite low blood/neuronal serotonin because their intraneuronal serotonin would be more efficiently released and then taken up by a fully functioning serotonin transporter.

Patients whose pain did not respond to amitriptyline were given a four-week course of pindolol as adjunct, based on experience in other studies ${ }^{(11)}$. Two patients reported vivid dreams and discontinued their treatment. A variety of drugs including carbamazepine, gabapentin, pregabalin or citalopram were used with patients not responding to amitriptyline, with varying degrees of success.

In view of the costs of treatment with relatively expensive drugs, genotyping may help identify patients who are more likely to respond in the long term. In a clinical practice setting, genetic and serotonin tests as described above involve taking a blood sample that costs around 60 euro per test and a result is obtained within one week. Good history-taking and long-term follow-up are important.

\section{Conclusions}

The incidence of 'SS', LS and 'LL' genotypes of the serotonin transporter gene-linked polymorphic region (HTTLPR) in patients with chronic persistent tension-type facial pain is very similar to that in matched pain-free controls. Clinical data on long-term outcomes suggests a better prognosis for patients with the LL genotype, although patient numbers are small and results have to be interpreted with caution. Patients with the SS or LS genotype seem to be more likely to need treatments other than first-line amitriptyline. As with previous studies, patients with chronic facial pain have lower blood serotonin compared to healthy controls. This is a consistent finding regardless of genotype.

\section{Acknowledgement}

The authors wish to acknowledge the assistance of Medical Laboratory Services at St James Hospital, Malta who collected and analysed blood serotonin, and of Dr Marisa Cassar of BioDNA Laboratories, who carried out genotyping on blood samples.

\section{Authorship contribution}

AMA: study design, patient recruitment, examination, testing, analysis; RM: study design, analysis.

\section{Conflict of interest}

No conflict of interest reported.

\section{Ethics approval and consent to participate}

Not applicable.

\section{Consent for publication}

Not applicable.

\section{Availability of data and materials}

Not applicable.

\section{Funding}

This study was self-funded by the authors.

\section{References}

1. Bendtsen L. Central sensitisation in tensiontype headache-possible pathophysiologica mechanisms. Cephalalgia 2000; 20:486-508.

2. Basbaum Al, Fields HL. Endogenous pain control system: brainstem spinal pathways and endorphin circuitry. Ann Rev Neurisci. 1984; 7: 309-338

3. Sawynok J, Esser MJ, Reid AR Antidepressants as analgesics: an overview of central and peripheral mechanisms of action. J Psychiatry Neurosci. 2001; 26:21-29

4. Rudnick G, Clark J. From synapse to vesicle: the reuptake and storage of biogenic amine neurotransmitters. Biochem Biopohys Acta 1993; 1144: 249-263

5. Barker EL, Blakely RD. Norepinephrine and Serotonin transporters, molecular targets of antidepressant druges. Part 1 Preclinical section, transmitter systems.
In: Floyd E Bloom, and David J Kupfer, Eds Neuropsychopharmacology: the fourth generation of progress, Raven Press, New York, 2000; Chap 28: Pp 321-334

6. Aymard N, Honore P, Carbaccia I Determination of 5-hydroxytryptamine and tryptophan by liquid chromatography in whole blood. Its interest for exploration of mental disorders. Prog NeuroPychopharmacol \& Biol Psychiat. 1994; 18: 
77-8

7. Beikmann SB, Tomlinson ID, Rosenthal et al. Serotonin uptake is largely mediated by platelets versus lymphocytes in peripheral blood. ACS Chem. Neurosci. 2013; 4:161-170

8. Xiao R, Beck O, Hjemdahl P. On the accurate measurement of serotonin in whole blood. Scan J Clin Lab Invest. 1998; 58: 505-510)

9. Hergovich $\mathrm{N}$, Aigner $\mathrm{M}$, Eichler $\mathrm{H}$ et al. Paroxetine decreases platelet serotonin storage and platelet function in human beings. Clin Pharmacol Therapeutics. 2000; 68: 435-442

10. Anthony M, Lance JW. Plasma serotonin in patients with chronic tension headaches. Neurol Neurosurg Psychiat. 1989; 52: 182184

11. Agius AM, Muscat R, Jones NS. Serial blood serotonin levels in a randomized controlled trial comparing the efficacy of low-dose amitriptyline, amitriptyline with pindolol and placebo in patients with chronic tension-type facial pain. Rhinology 2013; 51:236-242

12. Agius AM, Jones NS, Muscat R. Three year follow-up of a cohort of 240 patients with chronic tension-type facial pain. J Laryngol Otol 2014; 128 (6): 518-526

13. Lesch KP, Balling $U$, Gross J et al. Organization of human serotonin transporter protein gene. J Neural Transm Gen Sect. 1994; 95: 157-162

14. Lesch KP, Wolozin BL, Murphy DL et al. Primary structure of the human platelet serotonin uptake site: identity with the brain serotonin transporter. J Neurochem. 1993, 60: 2319-2322

15. Saier MH. A functional-phylogenetic system for the classification of transport proteins. J Cell Biochem. 1999, 75: 84-94

16. Hells A Teufel A, Petri S et al. Allelic variation of human serotonin transporter gene expression. J Neurochem 1996, 66: 26212624

17. Caspi A, Sugden K, Moffitt TE et al. Influence of life stress on depression: moderation by a polymorphism in the 5-HTT gene. Science 2003, 301 (5631):386-389

18. Lesch KP, Bengel D, Hells A et al. Association of anxiety related traits with a polymorphism in the serotonin transporter regulator region. Science 1996: 274: 1527-1531

19. Murphy DL, Lesch KP. Targeting the murine serotonin transporter: insights into human neurobiology. Nat Rev Neurosci 2008, 9: 85-96

20. Wendland, JR, Martin BJ, Lesch KP et al. Simultaneous genotyping of four functional loci of human SLC6A4 with a re-appraisal of 5-HTTLPR and rs25531. Molecular Psychiatry 2006, 11: 224-226

21. Kosek $E$, Jensen $K R$, Lonsfdorf $T B$ et al. Genetic variation in the serotonin transporter gene (5-HTTLPR, rs25541) influences the analgesic response to the short acting opiod Remifentanil in humans. Mol Pain. 2009; 5: 37-44

22. Park J, Kim J, Lee HK et al. Serotonin trans- porter polymorphism and harm avoidance personality in chronic tension-type headache. Headache 2004; 44: 1005-1009

23. Maurex L, Zaboli G, Ohman A et al. The serotonin transporter gene polymorphism (5-HTTLPR) and affective symptoms among women diagnosed with borderline personality disorder. Eur Psych. 2010; 25: 19-25

24. Greenberg BD, Tolliver TJ, Huang SJ et al. Genetic variation in the serotonin transporter region affects serotonin uptake in human blood platelets. Am J Med Genet. 1999; 88: 83-87

25. Lindstedt F, Berrebi J, Greayer E, Lonsdorf TB, Schalling M, et al. Conditioned Pain Modulation Is Associated with Common Polymorphisms in the Serotonin Transporter Gene. PLOS ONE.2011; 6(3): e18252. https://doi.org/10.1371/journal. pone. 0018252

26. Palit S, Sheaff RJ, France CR et al., Serotonin transporter gene (5-HTTLPR) polymorphisms are associated with emotional modulation of pain but not emotional modulation of spinal nociception. Biol Pscyhol. 2011 Mar; 86 (3): 360-9.

27. Kunz M, Hennig J, Karmann AJ, Lautenbacher S. Relationship of 5-HTTLPR Polymorphism with various factors of pain processing: Subjective experience, Motor responsiveness and Catastrophizing. PLOS One 2016 Apr 4; 11(4): e0153089

28. Cui W, Yu X, Zhang $H$. The serotonin transporter gene polymorphism is associated with the susceptibility and the pain severity in idiopathic trigeminal neuralgia patients. Headache Pain 2014 Jun; 20: 15-42.

29. Hooten WM, Townsend CO, Sletten CD. The triallelic serotonin transporter gene polymorphism is associated with depressive symptoms in adults with chronic pain. Pain Res 2017 May 9; 10: 1071-1078.

30. International Headache Society criteria 2013,found at https://ichd-3.org/

31. Agius AM. Chronic sinusitis in Maltacorrelation between symptoms and $\mathrm{CT}$ scan. Rhinology 2010; 48: 59-64

32. Agius AM. Long-term follow-up of patients with facial pain in chronic rhinosinusitiscorrelation with nasal endoscopy and CT. Rhinology. 2010;48; 65-70

33. Zinreich SJ. Rhinosinusitis: radiologic diagnosis. Otolaryngol Head Neck Surg. 1997; 117 (Suppl): S27-34

34. Kuhn FA. Role of endoscopy in the management of chronic rhinosinusitis. Ann Otol Rhinol Laryngol. 2004; 193(Suppl): 15-18

35. Delgado PL. Serotonin nor-adrenaline reuptake inhibitors: New hope for the treatment of chronic pain. Int J Psych Clin Prac. 2006 10: 16-21

36. Yucel B, Kora K, Ozyalcin S et al . Depression automatic thoughts, alexithymia and assertiveness in patients with tension-type headache. Headache 2002; 42: 194-199

37. Hamilton M. A rating scale for depression J Neurol Neurosurg Psychiatry. 1960; 23 $56-62$
38. Xiao R, Beck O, Hjemdahl P. On the accurate measurement of serotonin in whole blood. Scan J Clin Lab Invest. 1998; 58: 505-510

39. Jensen R, Hindberg I. Plasma serotonin increase during episodes of tension-type headache. Cephalalgia 1994; 14: 219-22

40. Bendtsen L, Jensen R. Hindberg I et al. Serotonin metabolism in chronic tensiontype headache. Cephalalgia 1997; 17: 843-8.

41. Ashina $\mathrm{S}$, Bendtsen $\mathrm{L}$, Ashina $\mathrm{M}$ et al Generalized hyperalgesia in patients with chronic tension-type headache. Cephalalgia 2006; 26: 940-948

42. Bendtsen L, Jensen R. Amitriptyline reduced myofascial tenderness in patients with chronic tension-tpe headache. Cephalalgia 2000; 20: 603-610

43. Coderre TJ, Katz J, Vaccarino AL et al. Contribution of central neuroplasticity to pathological pain: a review of clinical and experimental evidence. Pain 1993; 52: 259285

44. Lamour Y, Guilbaud G, Willer JC. Altered properties and laminar distribution of neuronal responses to peripheral stimulation in the $\mathrm{Sml}$ cortex of the arthritic rat. Brain Res 1983; 273 : 183-187

45. Pielsticker A, Haag G, Zaudig M et al. Impairment of pain inhibition on chronic tension-type headache. Pain 2005; 118: 215223

46. Yarnitsky D. Conditioned pain modulation (the diffuse noxious inhibitory control-like effect): its relevance for acute and chronic pain states Curr Opin Anaesthesiol. 2010; 23 (5), 611-615

47. Kosek E,Hansson P. Modulatory influence on somatosensory perception from vibration and heterotopic noxious conditioning stimulation (HNCS) in fibromyalgia patients and healthy subjects. Pain. 1997; 70: 41-51

48. Villanueva L. Diffuse Noxious Inhibitory Control (DNIC) as a tool for exploring dysfunction of endogenous pain modulatory systems. Pain. 2009; 143(3): 161-162

49. Treister R, Pud D, Ebstein RP, et al. Association between polymorphisms in serotonin and dopamine-related genes and endogenous pain modulation. J Pain 2011 Aug; 12 (8): 875-83

50. Hermans L, van Oosterwijck J, Goubert D et al. Inventory of personal factors influencing conditioned pain modulation in healthy people: a systematic literature review. Pain Pract. 2016 Jul; 16(6):758-769

51. Kennedy DL, Kemp HI, Ridout D, Yarnitsky D et al. Reliability of conditioned pain modulation: a systematic review. Pain 2016; 157, 2410-2419

52. Hariri AR, Mattay VS, Tessitore A, et al. Serotonin transporter genetic variation and the response of the human amygdala. Science. 2002;297, 400-403

53. Eisenberg DT, Hayes MG. Testing the null hypothesis: comments on culture-gene coevolution in individualism-collectivism and the serotonin transporter gene. Proceedings: Biological Sciences. 2011; 278 
(1704): $329-32$

54. Lesch KP, Gutnecht L. Pharmacogenetics of the serotonin transporter. Progress in Neuro-Psychopharmacology and Biological Psychiatry. 2005; 29: 1062-1073

55. Grech C, Bezzina Wettinger S, Farrugia R. Local allele frequencies of the 5-HTTLPR serotonin transporter promoter polymorphism. Malta Journal of Health Sciences 2019; 6(1), 14-21

56. Agius AM, Muscat R, Jones NS. Serial blood serotonin levels in a randomized controlled trial comparing the efficacy of low-dose amitriptyline, amitriptyline with pindolol and placebo in patients with chronic tension-type facial pain. Rhinology 2013; 51:236-242.77-8
Dr Adrian M Agius

St Anne's Clinic

Triq Kanonku Karmenu Pirotta

B'Kara

Malta BKR 1111

E-mail:

adrianagius@stannesclinic.com

ISSN: 2589-5613 / @2019 The Author(s). This work is licensed under a Creative Commons Attribution 4.0 International License. The images or other third party material in this article are included in the article's Creative Commons license, unless indicated otherwise in the credit line; if the material is not included under the Creative Commons license, users will need to obtain permission from the license holder to reproduce the material. To view a copy of this license, visit http://creativecommons.org/licenses/by/4.0/ 